\title{
Avaliação do extrato hidroalcoólico de Aroeira (Schinus terebinthifolius Raddi) no processo de cicatrização de feridas em pele de ratos ${ }^{1}$
}

\author{
Evaluation of hydroalcoholic extract of Aroeira (Shinus Terebinthifolius Raddi) in the \\ healing process of wound skin in rats
}

\begin{abstract}
Manoel Lages Castelo Branco Neto ${ }^{2}$, Jurandir Marcondes Ribas Filho ${ }^{3}$, Osvaldo Malafaia ${ }^{3}$, Marco Antonio de Oliveira Filho ${ }^{5}$, Nicolau Gregori Czeczko ${ }^{3}$, Sonia Aoki ${ }^{4}$, Regina Cunha ${ }^{4}$, Vinicius Ribas Fonseca ${ }^{5}$, Humberto Marten Teixeira $^{4}$, Luiz Roberto Farion de Aguiar $^{4}$
\end{abstract}

1. Trabalho realizado no laboratório de Pesquisas do Centro de Ciências Biológicas e da Saúde da Universidade Federal do Maranhão

2. Professor do Departamento de Cirurgia da Universidade Federal do Maranhão

3. Professor Doutor em Cirurgia

4. Aluno de Pós-Graduação - Mestrado

5. Aluno de Pós-Graduação - Doutorado

\section{RESUMO}

Objetivo: Avaliar o efeito cicatrizante da administração tópica do extrato hidroalcoólico de Aroeira em feridas abertas na região dorsocostal de ratos. Métodos: Utilizou-se 60 ratos Wistar, machos, que tiveram retirado fragmentos de pele com dois centímetros de diâmetro, sob anestesia inalatória com éter etílico. Foram divididos em dois grupos de 30 animais: o grupo Aroeira, que recebeu aplicação do extrato hidroalcoólico da planta, e o grupo controle, que recebeu aplicação de solução salina a $0,9 \%$. Cada grupo foi subdividido em 3 com 10 animais cada para serem observados aos sete, 14 ou 21 dias. As áreas das lesões foram analisadas pelo aspecto macroscópico e por planimetria digital. Os espécimes ressecados das feridas foram analisados por microscopia ótica em colorações de hematoxilina-eosina e tricrômio de Masson. Resultados: Os achados macroscópicos demonstraram reepitelização completa mais precoce no grupo controle aos 14 dias. Pela planimetria digital as áreas médias das feridas dos ratos do grupo controle $\left(0,5278 \mathrm{~cm}^{2}\right)$ foram menores que as das feridas dos ratos do grupo Aroeira $\left(0,6897 \mathrm{~cm}^{2}\right)$, com significância estatística aos 14 dias de pós-operatório $(\mathrm{p}=0,036)$. O estudo histológico demonstrou diferença estatística $(p=0,023)$ em relação às células mononucleares no $14^{\circ}$ dia de avaliação, com maior número no grupo Aroeira, não havendo diferenças significantes em relação aos outros parâmetros em nenhum dos dias estudados. Conclusão: O extrato hidroalcoólico de Aroeira retardou a reepitelização das feridas da pele dos ratos Descritores: Cicatrização de Feridas. Fitoterápico. Anacardiaceae (Schinus terebinthifolius Raddi)

\begin{abstract}
Purpose: To evaluate the healing effect of the topic administration of the hydroalcoholic extract of Aroeira in open wounds in the dorsocostal region of rats. Methods: Sixty Wistar rats, males, were used. In all animals one skin fragment was removed, with two centimeters in diameter. Inhalatory anesthesia with ethyl ether was done, The rats were divided in two groups of 30 animals: Aroeira group, submitted to an topic application of the hydralcoholic extract of the plant, and control group, with the same process but with $0.9 \%$ saline solution. Each group was divided in three sub-groups of 10 animals according to the period of observation: 7, 14 and 21 days. The areas of the injuries were analyzed by the macrocospic aspect and digital planimetry, and the resected segments of the wounds were studied by optic microscopy stainned with hematoxilin-eosine and trichromium of Masson. Results: The macrocospic findings showed early complete reepitelization in the control group by the 14th day. According to the digital planimetry the average wound areas of the rats from the control group $\left(0.5278 \mathrm{~cm}^{2}\right)$ had been smaller than those from the wounds of the rats of the Aroeira group $\left(0.6897 \mathrm{~cm}^{2}\right)$, with statistical significance to the 14 th day $(\mathrm{p}=0.036)$. The hystologic study showed statistical difference $(\mathrm{p}=0.023)$ regarding the mononuclear cells in 14th day of evaluation, with larger number in the Aroeira group, without significant differences regarding other parameters in all the remaining days. Conclusion: The topic use of the hydralcoholic extract of Aroeira delayed the reepitelization of the skin wounds in rats
\end{abstract}

Key words: Wound Healing. Skin. Phitotherapy. Anacardiaceae (Schinus terebinthifolius Raddi)

\section{Introdução}

Após um ferimento, inicia-se seqüência de eventos biológicos, dinâmicos e complexos, que visam promover o reparo da lesão que caracterizam a cicatrização. Ela é formada por três fases evolutivas sobrepostas: fase inicial ou inflamatória, fase proliferativa ou de fibroplasia e fase de remodelação ou maturação $0^{1,2}$.

Desde os primórdios, o homem tenta interferir nesse processo, procurando diminuir o seu período e buscando 
melhores resultados, quer estéticos quer funcionais. Neste processo evolutivo as plantas obtiveram lugar de destaque. A utilização de plantas com fins medicinais, conhecida atualmente como fitoterapia, durante vários séculos constituiu a base terapêutica da prática médica. A partir do século XIX, com o progresso da química, as moléculas ativas foram extraídas das plantas e reproduzidas artificialmente, o que, somado ao desenvolvimento da indústria farmacêutica, levou a maioria da população a substituir progressivamente as plantas in natura pelas drogas, não por ineficiência das primeiras, mas, principalmente, pela maior oferta dos medicamentos sintéticos que, pela comodidade, foram mais aceitos pelas populações, principalmente dos centros urbanos maiores m $^{3,4,5,7}$.

Dentre as plantas de grande uso popular encontra-se a Aroeira, que tem como nome científico Schinus terebinthifolius Raddi.

No Brasil, a Aroeira é planta comum da vegetação litorânea dos estados nordestinos. Sua casca é usada como antiinflamatório e cicatrizante ${ }^{4,6,13}$.

Apesar do grande e antigo emprego popular, na revisão bibliográfica, não foi encontrado trabalho científico estudando o uso tópico da Aroeira como cicatrizante o que motivou a realização desta pesquisa, que tem como objetivo verificar o efeito do extrato hidroalcóolico da Aroeira no processo de reparação tecidual de feridas induzidas na pele de ratos, mediante avaliação de parâmetros macroscópicos e histológicos.

\section{Métodos}

Este estudo foi realizado no Laboratório de Pesquisa do Departamento de Fisiologia e Farmacologia do Centro de Ciências Biológicas e da Saúde da Universidade Federal do Maranhão (UFMA) em São Luiz - MA e aprovado pelo Comitê de Ética em Pesquisa da UFMA.

\section{Preparo do fitoterápico}

O extrato hidroalcoólico de Aroeira foi preparado, a partir da entrecasca seca de parte aérea de uma única árvore adulta $^{17}$. O material vegetal $(8.000 \mathrm{~g}$ de entrecasca seca de Aroeira) foi colocado para secagem em temperatura ambiente; depois triturado com faca e colocado durante 24 horas em estufa com temperatura entre $45^{\circ} \mathrm{C}$ e $50^{\circ} \mathrm{C}$ para retirar a umidade. Em seguida, foi submetido a processo de moagem, com obtenção de pó. Este material foi pesado e depositado em recipiente de vidro com adição de solução hidroalcoólica a 70\% na proporção de 1:3 do pó. A mistura resultante permaneceu por 12 horas sendo agitada durante cinco minutos a cada duas horas, passando então por dois processos de filtração simples, sob pressão reduzida, obtendo-se ao final $3.450 \mathrm{ml}$ de extrato bruto de coloração lilás. O extrato bruto foi concentrado em evaporador rotativo sob pressão reduzida, com temperatura entre $55^{\circ} \mathrm{C}$ e $60^{\circ} \mathrm{C}$, para eliminação total do solvente.

O produto obtido após concentração apresentou-se sob a forma de pasta, da qual foi retirada amostra para testes farmacológicos. Foi ela então diluída em água destilada até obter- se extrato hidroalcoólico na concentração de $100 \mathrm{mg} / \mathrm{ml}$ que foi mantido em refrigerador a $10^{\circ} \mathrm{C}$ até ser utilizado ${ }^{12}$.

\section{O experimento}

Foram utilizados 60 ratos (Rattus novergicus albinus, Rodentia mammalia), da linhagem Wistar, machos, com peso médio de $156,31 \mathrm{~g}$.

Os animais foram divididos aleatoriamente em dois grupos de 30: Grupo Controle (Gc) e Grupo Aroeira (Ga). O Gc correspondia aos animais submetidos ao tratamento cirúrgico com aplicação de solução salina a $0,9 \%$ e o Ga, ao grupo de ratos submetidos ao tratamento cirúrgico e aplicação de extrato hidroalcoólico de Aroeira. Cada grupo (Gc e Ga) foi dividido em três subgrupos de 10 animais de acordo com o período de avaliação (sete, 14 e 21 dias de pós-operatório).

Para indução anestésica, cada animal foi colocado em campânula de plástico fechado, contendo algodão hidrófilo umedecido com éter etílico ${ }^{19}$.

Realizou-se epilação na região dorsal, em área de $24 \mathrm{~cm}^{2}$ ( $6 \mathrm{~cm}$ de comprimento $\mathrm{x} 4 \mathrm{~cm}$ de largura), localizada caudalmente a uma linha imaginária que passasse pelos membros anteriores. No centro da área epilada foi realizada demarcação na pele de cada rato por rotação da borda cortante de demarcador (punch) metálico com $2 \mathrm{~cm}$ de diâmetro.

Realizou-se então ressecção de segmento de pele circular, seguindo a demarcação do punch, aprofundando-se a incisão até expor a fáscia muscular dorsal.

Concluída hemostasia, foi realizada a primeira administração tópica, na ferida operatória cruenta, de $0,1 \mathrm{ml}$ do extrato hidroalcóolico de Aroeira por meio de seringa de $1 \mathrm{ml}$, sem agulha, nos animais do Ga. Mesmo volume de solução salina foi aplicado no Gc.

Todos os animais foram sacrificados nas datas programadas, por inalação de vapor de éter, até parada cardiorespiratória.

\section{Avaliação macroscópica}

$\mathrm{Na}$ análise macroscópica das feridas operatórias, foram verificadas a ocorrência de hemorragia (sim ou não), a presença e extensão de crostas (total, parcial ou ausente), a presença de secreção (sim ou não) e a reepitelização (completa, parcial ou ausente).

\section{Planimetria digital}

Após sacrificados, cada animal foi colocado sobre prancha cirúrgica revestida com papel cartão preto e teve a lesão fotografada por câmera digital (Modelo Powershot A100 ${ }^{\circledR}$, Canon, Japão), mantida em tripé a uma distância constante de $34 \mathrm{~cm}$, com aproximação de 1,3x e resolução de 1280 x 960 pontos. Este procedimento visou obter imagens para avaliar a cicatrização por planimetria digital através do programa de computador AutoCad $14^{\circledR}$.

Na mesma ocasião, foram realizadas medições do maior diâmetro da ferida de cada animal, com paquímetro digital milimetrado, para cálculo da área real durante a planimetria 
digital (Figura 1)

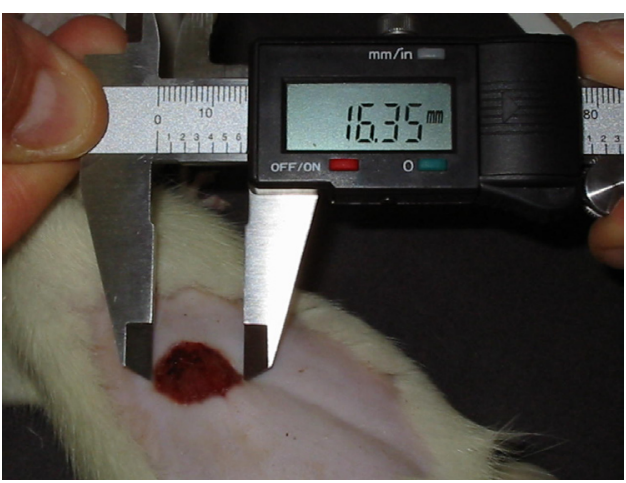

FIGURA 1 - Medição da ferida com paquímetro digital

A imagem (fotografia digital) foi importada para o programa de computador AutoCad $14^{\mathbb{R}}$, no qual realizouse delimitação na periferia da ferida (poliline) (Figura 2) e cálculo da sua área, utilizando a medida do maior diâmetro, obtida com paquímetro digital, para transformação em tamanho real.

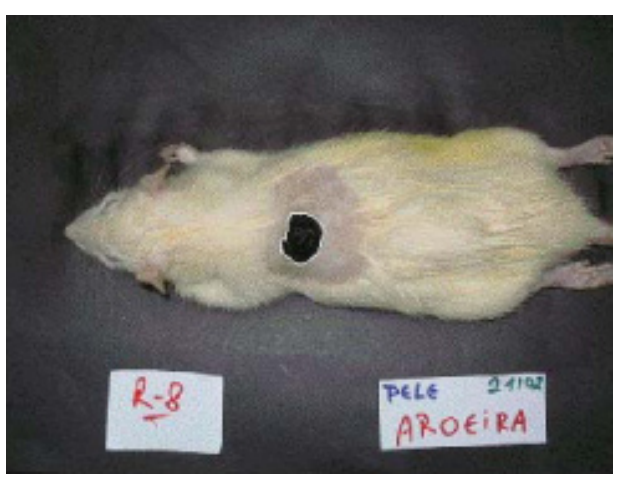

FIGURA 2 - Delimitação da área da ferida no programa AutoCad $14^{\circledR}$

\section{Avaliação microscópica}

Cada ferida cirúrgica foi dissecada com margem de $1 \mathrm{~cm}$ de pele íntegra em torno da lesão, com profundidade até a musculatura dorsal do animal, sendo a peça cirúrgica colocada em recipiente plástico com formol a $10 \%$.

Foram realizadas colorações histológicas por HE para analisar morfologicamente os tecidos, e tricrômio de Masson, para observação de fibras colágenas. Nas observações de microscopia óptica, foram avaliados os seguintes parâmetros: proliferação vascular, células polimorfonucleares, células mononucleares, proliferação fibroblástica, fibras colágenas e reepitelização. Para proliferação vascular, células polimorfonucleares, células mononucleares, proliferação fibroblástica e fibras colágenas foram atribuídas quatro graduações: ausente, discreta, moderada e acentuada. Para a reepitelização foram três: ausente, parcial e completa.

\section{Análise estatística}

Os dados foram analisados utilizando-se o programa Statistica for Windows 5.1 ${ }^{\circledR}$. Para avaliar em conjunto os efeitos dos grupos (Ga e Gc), do tempo (sete, 14 e 21 dias) e para interação entre eles foi realizada ANOVA com dois fatores para a variável numérica área $(\mathrm{cm} 2)$. As comparações das áreas médias das feridas dos animais do Gc e do Ga em cada um dos dias de estudo foram feitas através do teste t de Student. As variáveis histológicas, foram analisadas pelo teste não-paramétrico de Mann-Whitney, e o teste de Kruskal-Wallis. O nível de significância (p) utilizado para se rejeitar a hipótese da nulidade foi de 0,05 .

\section{Resultado}

\section{Avaliação macroscópica}

Os achados macroscópicos demonstraram reepitelização completa mais precoce no grupo controle aos 14 dias. Neste período, foram cinco ratos do grupo controle reepitelizados e cinco sem reepitelização completa; no gupo Aroeira, somente um foi reepitelizado, com nove sem reepitelização completa. Aos 21 dias, todos os ratos do grupo controle estavam reepitelizados; no grupo Aroeira, seis estavam reepitelizados neste período, mas quatro não mostravam reepitelização completa.

\section{Planimetria digital}

Aos sete dias de avaliação a média das áreas das feridas dos ratos do Ga foi maior que a dos ratos do Gc (Tabela 1).

TABELA 1 - Áreas das lesões $\left(\mathrm{cm}^{2}\right)$ - Ga e Gc sete dias de pós-operatório

\begin{tabular}{cccc}
\hline \multicolumn{2}{c}{ Ga - 7 Dias } & \multicolumn{2}{c}{ Gc - 7 Dias } \\
\hline Ratos & Áreas & Ratos & Áreas \\
1 & 1,4815 & 1 & 1,3873 \\
2 & 1,4540 & 2 & 1,7583 \\
3 & 1,5293 & 3 & 1,1865 \\
4 & 2,0735 & 4 & 1,5727 \\
5 & 2,3710 & 5 & 0,7367 \\
6 & 1,4656 & 6 & 1,3643 \\
7 & 1,4330 & 7 & 1,2706 \\
8 & 1,1800 & 8 & 2,1371 \\
9 & 2,0156 & 9 & 1,5454 \\
10 & 1,3782 & 10 & 1,7339 \\
Média & $\mathbf{1 , 6 3 8 1 7}$ & & $\mathbf{1 , 4 6 9 2 8}$ \\
\hline
\end{tabular}

Aos 14 dias de avaliação, a média das áreas das feridas dos ratos do Ga foi maior que a dos ratos do Gc, com diferença superior que aos sete dias (Tabela 2).

Aos 21 dias de avaliação, a média das áreas das feridas dos ratos do Ga permaneceu maior que a média das áreas dos ratos do Gc, porém com menor diferença (Tabela 3). 
TABELA 2 - Áreas das lesões $\left(\mathrm{cm}^{2}\right)$ - Ga e Gc 14 dias de pós-operatório

\begin{tabular}{cccc}
\hline \multicolumn{2}{c}{ Ga - 14 Dias } & \multicolumn{2}{c}{ Gc - 14 Dias } \\
\hline Ratos & Áreas & Ratos & Áreas \\
1 & 0,3659 & 1 & 0,0100 \\
2 & 0,1618 & 2 & 0,0012 \\
3 & 0,0480 & 3 & 0,0530 \\
4 & 0,4551 & 4 & 0,1315 \\
5 & 0,0204 & 5 & 0,0797 \\
6 & 0,9191 & 6 & 0,2034 \\
7 & 0,1272 & 7 & 0,3345 \\
8 & 0,1969 & 8 & 0,1164 \\
9 & 1,3173 & 9 & 0,0386 \\
10 & 0,6618 & 10 & 0,0185 \\
Média & $\mathbf{0 , 4 2 7 3 5}$ & & $\mathbf{0 , 0 9 8 6 8}$ \\
\hline
\end{tabular}

TABELA 3 - Áreas das lesões $\left(\mathrm{cm}^{2}\right)$ - Ga E Gc 21 dias de pós-operatório

\begin{tabular}{cccc}
\hline \multicolumn{2}{c}{ Ga - 21 Dias } & \multicolumn{2}{c}{ Gc - 21 Dias } \\
\hline Ratos & Áreas & Ratos & Áreas \\
1 & 0 & 1 & 0 \\
2 & 0,0064 & 2 & 0 \\
3 & 0 & 3 & 0 \\
4 & 0,0180 & 4 & 0 \\
5 & 0,0180 & 5 & 0 \\
6 & 0 & 6 & 0 \\
7 & 0 & 7 & 0 \\
8 & 0,0010 & 8 & 0 \\
9 & 0 & 9 & 0 \\
10 & 0 & 10 & 0 \\
Média & $\mathbf{0 , 0 0 3 7 2}$ & & $\mathbf{0}$ \\
\hline
\end{tabular}

O teste $t$ de Student demonstrou áreas maiores no Ga, com diferença estatística significante somente no $14^{\circ}$ dia.

\section{Avaliação microscópica}

A Tabela 4 demonstra comparação histológica entre Gc e Ga aos sete dias de estudo, não apresentando diferença com significância estatística em nenhum item analisado.

Apesar de não ter ocorrido diferença estatística significativa, aos sete dias de estudo houve proliferação vascular mais intensa no Gc e o Ga apresentou maior número de células mononucleares, conforme visibilizado na Figura 3.

Os resultados histológicos comparados, entre Ga e Gc aos 14 dias de estudo, estão demonstrados na Tabela 5, na qual observa-se diferença significante somente em relação a células mononucleares $(\mathrm{p}=0,023)$, com maior incidência no Ga.

Mesmo sem resultado significante, na Figura 4, pode ser verificado, aos 14 dias de pós-operatório, proliferação fibroblástica com formação recente de colágeno mais intensa no Ga.

Os resultados histológicos comparados intergrupos aos 21 dias de pós-operatório estão demonstrados na Tabela 6 ,
TABELA 4 - Comparação histológica intergrupos Gc - Ga aos sete dias de pós-operatório

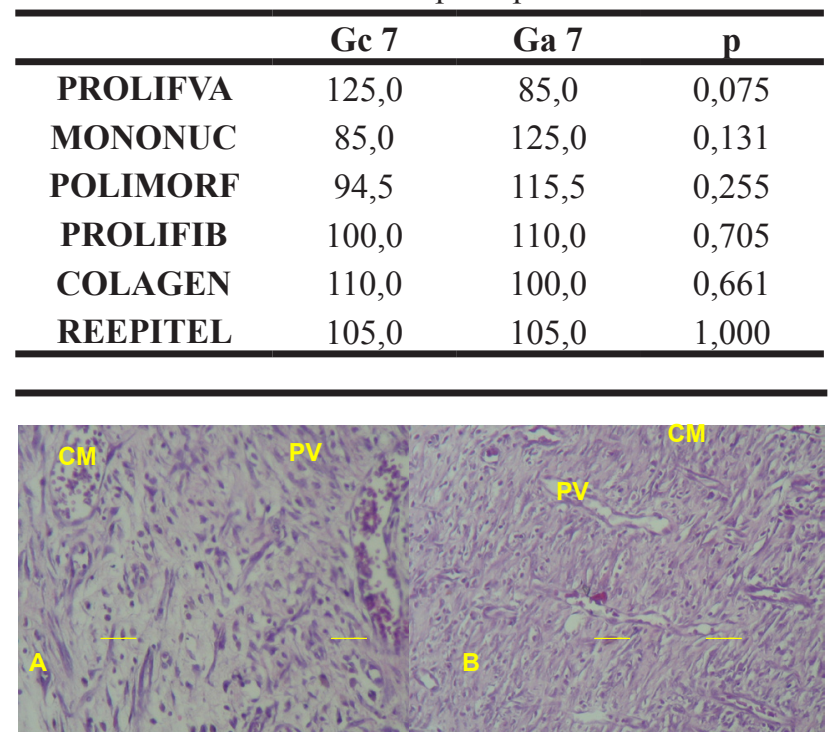

FIGURA 3 - Fotomicrografia de tecido de reparação da pele de ratos - sete dias de pós-operatório. Legenda: $\mathrm{A}=$ Rato $7 \mathrm{Ga} \mathrm{B}=$ Rato $3 \mathrm{Gc}$ - Coloração HE, 10 X. Nota: Proliferação Vascular (PV) mais intensa em Gc (B). Células Mononucleares (CM) em maior número em $\mathrm{Ga}(\mathrm{A})$.

TABELA 5 - Comparação histológica intergrupos Gc - Ga aos 14 dias de pós-operatório

\begin{tabular}{cccc}
\hline & Gc 14 & Ga 14 & $\mathbf{p}$ \\
\hline PROLIFVA & 111,5 & 98,5 & 0,557 \\
MONONUC & 75,0 & 135,0 & $0,023^{*}$ \\
POLIMORF & 98,0 & 112,0 & 0,574 \\
PROLIFIB & 115,0 & 95,0 & 0,450 \\
COLAGEN & 95,0 & 115,0 & 0,450 \\
REEPITEL & 115,0 & 95,0 & 0,450 \\
\hline
\end{tabular}

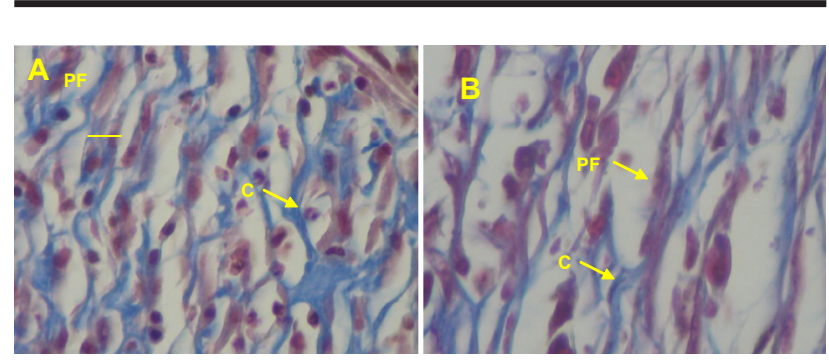

FIGURA 4 - Fotomicrografia de tecido de reparação da pele de ratos - 14 dias de pós-operatório. Legenda: A=Rato 9Ga $\mathrm{B}=$ Rato $7 \mathrm{Gc}$ Coloração por tricrômio de Masson, 40x. Nota: Proliferação fibrobástica (PF) com formação recente de colágeno (C) mais intensa no $\mathrm{Ga}$ 
não havendo diferença estatística significante.

TABELA 6 - Comparação histológica intergrupos Gc - Ga aos 21 dias de pós-operatório

\begin{tabular}{cccc}
\hline & Gc 21 & Ga 21 & p \\
\hline PROLIFVA & 110,0 & 100,0 & 0,317 \\
MONONUC & 80,0 & 130,0 & 0,059 \\
POLIMORF & 95,0 & 115,0 & 0,146 \\
PROLIFIB & 115,0 & 95,0 & 0,276 \\
COLAGEN & 88,5 & 121,5 & 0,154 \\
REEPITEL & 115,0 & 95,0 & 0,146 \\
\hline
\end{tabular}

\section{Discussão}

A OMS estima que $80 \%$ da população de países em desenvolvimento é tratada com técnicas da medicina popular e desse total, $85 \%$ usam produtos de origem vegeta ${ }^{2}$.

A Aroeira-da-praia é planta bastante utilizada como medicamento popular, administrada por via oral ou tópica, para cura de várias doenças, com efeitos diversos, incluindo ações antimicrobianas, antiinflamatórias e cicatrizantes. Concordando-se com Oliveira ${ }^{12}$, representa opção de baixo custo, fácil acesso e manipulação, entretanto, na maioria das vezes, é usada sem conhecimento científico.

A avaliação macroscópica das lesões visou observar, principalmente, hemorragias, presença de crostas e presença de secreções. Durante o estudo, não ocorreu nenhum episódio de hemorragia, apenas sangramentos inerentes aos procedimentos cirúrgicos, controlados somente por compressão com gazes, à semelhança do referido por vários autores ${ }^{5,7,9,10,18,20}$.

As crostas estavam presentes em maior extensão nas feridas do $7^{\circ}$ dia de avaliação, em ambos os grupos. $\mathrm{O}$ mesmo foi observado por Bevilacqua ${ }^{3}$ e Simões ${ }^{15}$, segundo os quais a solução de continuidade causada pela remoção do fragmento de pele é inicialmente preenchida por coágulo, fibrina e exsudato inflamatório, que originam crosta fibrinoleucocitária. A presença de exsudato inflamatório justifica também a ocorrência de secreções observadas aos sete dias de estudo, em dois animais do subgrupo Ga e em um animal do subgrupo Gc.

De acordo com Gabbiani ${ }^{8}$, o processo de cicatrização das feridas abertas é diferen te das fechadas, apesar das reações após as lesões serem idênticas para os dois tipos, ocorrendo exsudação inflamatória, neoformação vascular, proliferação celular, migração celular e epitelização a partir das bordas.

Neste estudo, as lesões de pele dos animais do Gc apresentaram contração e reepitelização macroscópicas mais precoces que as dos animais do $\mathrm{Ga}$, pois, no $14^{\circ}$ dia de avaliação, cinco ratos do Gc já estavam com as feridas completamente reepitelizadas, enquanto no Ga este processo só ocorreu na ferida de um rato. No $21^{\circ}$ dia de análise, todas feridas dos animais do Gc estavam completamente reepitelizadas, enquanto que, no Ga, quatro não apresentaram reepitelização completa. Resultados semelhantes foram obtidos em estudos de uso tópico com outros fitoterápicos, como copaíba $^{5}$ e arnica $^{10}$; ao contrário da utilização de papaína ${ }^{14}$ e rosa mosqueta $^{9}$ que favoreceram a reepitelização.

Conforme demonstrado nos resultados deste estudo, ocorreu efeito estatisticamente significante em favor do grupo Ga que apresentou áreas de regeneração maiores que as do Gc, ao contrário do relatado por VIANA ${ }^{16}$, estudando outra anacardiácea.

Embora em dimensões diferentes, os resultados demonstram que houve diminuição progressiva nas áreas médias das feridas de todos os animais em todos os dias de avaliação. A explicação para este fato pode ser o que SANCHEZ $\mathrm{NETO}^{14}$ diz serem as feridas abertas submetidas a um processo de contração na tentativa de reparação da lesão.

Realizou-se ainda o teste $t$ de Student, com a finalidade de verificar a diferença de médias entre os grupos em cada dia analisado. Constatou-se que, no $14^{\circ}$ dia de pós-operatório, houve diferença estatística significativa $(p=0,036)$, com média de áreas no Ga maior que média de áreas no Gc, demonstrando que, neste período de avaliação, o extrato hidroalcoólico de Aroeira retardou o processo de reparação tecidual, à semelhança de estudos com outros fitoterápicos ${ }^{5,10}$.

A utilização do programa de computador AutoCad $14^{\circledR}$ para calcular áreas dos ferimentos em fotografias digitais mostrou-se eficaz com capacidade de analisar superfícies irregulares, sendo de fácil execução e passível de revisão.

Em relação à proliferação vascular, observou-se comportamento semelhante em ambos os grupos durante os três dias de estudo, com valores maiores no $7^{\circ}$ dia, e diminuição progressiva no $14^{\circ}$ e $21^{\circ}$ dia 5,10 . Avaliações semelhantes foram citadas por outros autores ${ }^{5,10}$ que observaram, dentro da massa de tecido de granulação, vasos sanguíneos dispostos perpendicularmente ao epitélio e que, com o evoluir do processo de reparação, iam se dispondo paralelamente e diminuíam de quantidade. Na comparação intergrupos foram verificadas diferenças significativas entre Ga e Gc aos 14 dias de pós-operatório, com valor maior no Ga, traduzindo, portanto, um processo inflamatório mais intenso neste grupo no dia referido.

Em relação às células polimorfonucleares a análise intragrupos demonstrou, tanto para o Ga como para o Gc, que os valores sofreram decréscimo significante, sendo progressivamente menores nos dias 14 e 21 em comparação ao $7^{\circ}$ dia. A comparação intergrupos não apresentou diferença significante. Estes achados estão de acordo com Sanchez Neto et al. ${ }^{14}$, segundo os quais os polimorfonucleares apresentam alta concentração no início do processo inflamatório, e depois diminuem gradativamente.

No $14^{\circ}$ e $21^{\circ}$ dias de avaliações, o Gc apresentou maior número de animais com reepitelização histológica completa das feridas; contudo, a análise estatística intergrupo para reepitelização não mostrou diferença significativa entre $\mathrm{Ga}$ e Gc nos dias estudados. Evoluções semelhantes foram relatadas por Modolin ${ }^{11}$, segundo o qual a reepitelização se inicia em torno de 10 a 15 horas após o trauma a partir das margens da ferida, através de células epiteliais, com movimentos amebóides sobre o tecido adjacente, com finalidade de recobri-la. 


\section{Conclusão}

O extrato hidroalcoólico de Aroeira retardou a reepitelização das feridas da pele dos ratos.

\section{Referências}

1. Araújo M. G. Atividade antioxidante da espécie Schinus terebinthifolius Raddi (Aroeira-da-praia). In: Reunião Nordestina de Botânica, 1996. Caderno de resumos. Universidade Federal do Rio Grande do Norte, 1996.

2. Balbachas A. As plantas curam. $2^{\text {nd }}$. São Paulo: Missionária, 1965.

3. Bevilacqua RG. Cicatrização. Manual do residente de cirurgia. $2^{\text {nd }}$. São Paulo: Pedagógica e Universitária, 1984.

4. Braga R. Plantas do nordeste, especialmente do Ceará. $3^{\text {nd }}$. Mossoró: Escola Superior de Agricultura de Mossoró, 1976.

5. Brito NMB. Aspectos morfológicos e morfométricos da cicatrização de feridas cutâneas abertas em ratos tratados com óleo de copaíba. [Dissertação- Mestrado]. São Paulo: Programa de Pós-graduação em Técnica Operatória e Cirurgia Experimenta, Escola Paulista de Medicina, Universidade de São Paulo; 1996.

6. Corrêa MP. Dicionário das Plantas Úteis no Brasil e das Exóticas Cultivadas. Brasília, DF: Ministério da Agricultura/IBDF, 1984 (Reimpressão sem alterações da edição publicada em 1926).

7. Facury Neto MA. Uso sistêmico da arnica (Solidago microglossa DC) em cicatrização de feridas cutâneas abertas em ratos. [Tese - Doutorado]. São Paulo: Programa de Pós-graduação em Técnica Operatória e Cirurgia Experimental. Escola Paulista de Medicina, Universidade de São Paulo; 2001.

8. Gabbiani G, Majno G. Dupuytren's contracture: fibroblast contraction? A ultrastructural study. Am J Pathol. 1972; 66: 131-8.

9. Marchini FB. Estudo morfológico e morfométrico da cicatrização de feridas cutâneas abertas em ratos albinos com e sem tratamento com óleo de rosa mosqueta. 1994. [Dissertação - Mestrado]. São Paulo: Programa de Pós-graduação em Técnica Operatória e Cirurgia Ex- perimental. Escola Paulista de Medicina, Universidade de São Paulo;1994.

10. Miranda LTGS.Uso da tintura de arnica em feridas cutâneas abertas em ratos. [Dissertação-Mestrado]. São Paulo: Programa de Pós-graduação em Técnica Operatória e Cirurgia Experimental, Escola Paulista de Medicina. Universidade Federal de São Paulo; 2001.

11. Modolin M; Bevilacqua RG. Cicatrização das feridas: Síntese das aquisições recentes. Rev Bras Clin Terap. 1985; 14: 208-13.

12. Oliveira AB. Espectrofotometria no controle de qualidade dos fitoterápicos da Schinus terebinthifolius Raddi. [Dissertação- Mestrado]. São Luis: Curso de Pós-graduação em Ciências da Saúde, Universidade Federal do Maranhão; 2001.

13. Rêgo TJAS. Fitogeografia das plantas medicinais do Maranhão. São Luís: EDUFMA/CORSUP, 1993. p. 27-43: Levantamento de plantas medicinais da região dos chapadões maranhenses.

14. Sanchez- Neto R. Aspectos morfológicos e morfométricos da reparação tecidual de feridas cutâneas de ratos com e sem tratamento com solução de papaína a $2 \%$. Acta Cir Bras. 1993; 8: 18-23.

15. Simões MJ, Cabral ACV, Boyaciyan K, Kulay Jr. L, Sasso WS. Aspectos ultra-estruturais dos fibroblastos e dos macrófagos durante o processo de reparação da pele de ratos. Rev Paul Med. 1986; 104: 132-5.

16. Viana GSB. Aroeira do Sertão (Myracodruon urundeva fr. All). $2^{\text {nd }}$. Fortaleza: Universidade Federal do Ceará, 1995.

17. Vilanova CM, Gonçalves J R S. Investigação fitoquímica das cascas e folhas da Schinus terebinthifolius Raddi. In: Congresso Norte e Nordeste de Farmacêuticos. São Luís: UFMA, 1999.

18. Uzunköy A, Akince OF, Coskun A, Aslan O, Kocyigit A. Effects of antiadhesive agents on the healing of intestinal anastomosis. Dis Colon Rectum. 2000; 43:370-5.

19. White M N, Johnson AC, Eger KL. Anesthesy in experimental surgery. Exp Surg. 1974; 1: 250-60.

20. Witte MB, Barbul A. Princípios gerais da cicatrização das feridas. Clin Cir Am N. 1997; 77:509-27.

\section{Correspondência}

Manoel Lages Castello Branco Neto

AV. Jerônimo de Albuquerque, 540

Bequimão - São Luís -MA

CEP: 65.060-642

Tel: (98) 3216-8510
Conflito de interesse: nenhum Fonte de financiamento: Capes

Recebimento: 28/01/2005

Revisão: 10/06/2005

Aprovação: 24/04/2006

\section{Como citar este artigo}

Branco-Neto MLC, Ribas-Filho JM, Malafaia O, Oliveira-Filho MA, Czeczko NG, Aoki S, Cunha R, Fonseca VR, Teixeira HM, Aguiar LRF.Avaliação do extrato hidroalcoólico de Aroeira (Schinus terebinthifolius Raddi) no processo de cicatrização de feridas em pele de ratos. Acta Cir Bras [periódico na Internet] 2006; Suppl 2:17-22. Disponível em URL: http://www.scielo.br/acb

Figuras coloridas disponíveis em $\underline{\text { http://www.scielo.br/acb }}$ 